\title{
Earthquake Clustering and Energy Release of the African-Arabian Rift System
}

\author{
by Thomas R. Hall, Casey W. Nixon, Derek Keir, Paul W. Burton, and Atalay Ayele
}

\begin{abstract}
The earthquakes associated with continental deformation are spatially and temporally variable and are fundamental in understanding fault activity and seismogenic hazards. We conduct $K$-means cluster analysis on seismicity in the AfricanArabian rift systems to create the first computationally objective analysis of the pattern of earthquakes. We use seismic moment to compute spatial variations in maximum credible earthquake (Mcred) and likely time to the next major release of seismic energy. Our best-fit model has 32 clusters of $\sim 100-400 \mathrm{~km}$ in length, with cluster size decreasing northward along the rift and cluster boundaries correlating with major structural segmentation of the rift. Mcred varies between $M_{\mathrm{w}} 5.2$ and 7.4 across the whole dataset, with the highest values estimated in portions of the rift where the majority of extension is accommodated by seismogenic failure.
\end{abstract}

\section{Introduction}

Earthquakes and associated faulting within tectonically active continental rifts such as in East Africa are important for accommodating crustal extension and also pose a hazard to life and infrastructure in a rapidly developing region (e.g., Chorowicz, 2005; Ayele et al., 2007; Craig et al., 2011; Goitom et al., 2017) (Fig. 1). Despite this, the spatial variability of the amount of faulting and timescales of successive earthquakes and resultant implications for seismogenic hazard remain poorly understood (e.g., Ebinger et al., 2013). To address this issue, we demonstrate the application of a method newly applied in seismology to investigate the clustering of earthquakes in East Africa to delineate and quantify behavior of discrete zones with similar seismogenic properties; such a method has the potential to be applied to other continental rifts.

Spatial zonation for hazard assessment is common practice in many seismogenic regions (Cornell, 1968; Petersen et al., 2007). These are often defined by source characteristics (e.g., Papaioannou and Papazachos, 2000) and surface manifestations of structural boundaries, such as fault traces (e.g., Petersen et al., 2007). However, the characterization of seismic sources is often inconsistent, resulting in disagreement between zonation models of the same area. An emerging method of hazard zonation is to delineate source zones based on the hypocentral distribution of seismicity using a $K$-means cluster analysis (Weatherill and Burton, 2009; Burton and Hall, 2014). A clustering analysis of instrumentally observed and historical seismicity is particularly useful in areas where physical characteristics (i.e., structural observations) of seismic sources are absent. Furthermore, a $K$-means cluster analysis can be uniformly applied to different regions because it is based on instrumental data and is statistically supported rather than being subject to interpretation of physical source characteristics.

The $K$-means cluster analysis has already been successfully applied to the Aegean region (Weatherill and Burton, 2009), Pakistan (Rehman et al., 2013, 2017), and the Sumatran fault (Burton and Hall, 2014) where the optimum cluster model correlates well with known structural segmentation of the fault. Here, we apply it to the entire East African rift (EAR) system where there are variations in the extent and quality of structural observations throughout the region. This makes it impossible to apply a uniform assessment based on physical source characteristics alone. Hence, the $K$-means cluster analysis is an ideal alternative for developing a uniform spatial zonation model for hazard assessment in East Africa. Furthermore, it provides us with a framework to quantify and assess the spatial and temporal patterns of seismic moment release, allowing us to estimate the potential magnitudes and time frames of future ruptures within individual clusters.

\section{Geological Setting}

The EAR, Red Sea, and Gulf of Aden rifts have formed during the last $\sim 35$ my from the separation between the Nubian, Somalian, and Arabian plates (e.g., McKenzie et al., 1970; Leroy et al., 2012) (Fig. 1d). Extension rates in these sectors are variable, occurring at $\sim 15-18 \mathrm{~mm} / \mathrm{yr}$ in the western Gulf of Aden and southern Red Sea rifts (e.g., Jestin et al., 1994; Vigny et al., 2006; McClusky et al., 2010) and a progressive southward decrease along the EAR from a maximum velocity of $\sim 7 \mathrm{~mm} / \mathrm{yr}$ in the north (McClusky et al., 2010; Kogan et al., 2012; Stamps et al., 2015). In the EAR, extension is localized in Proterozoic-Precambrian orogenic 
(a)

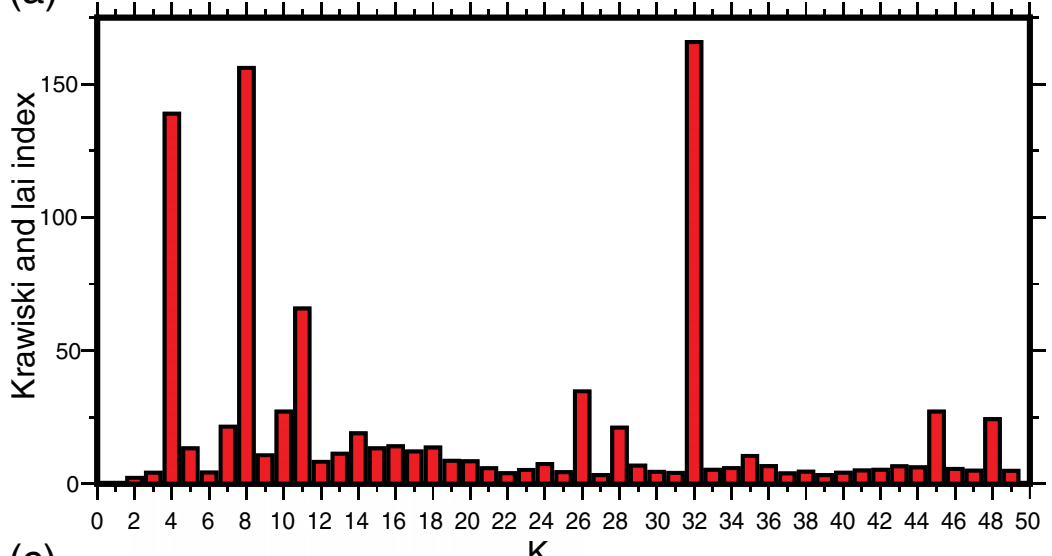

(c)
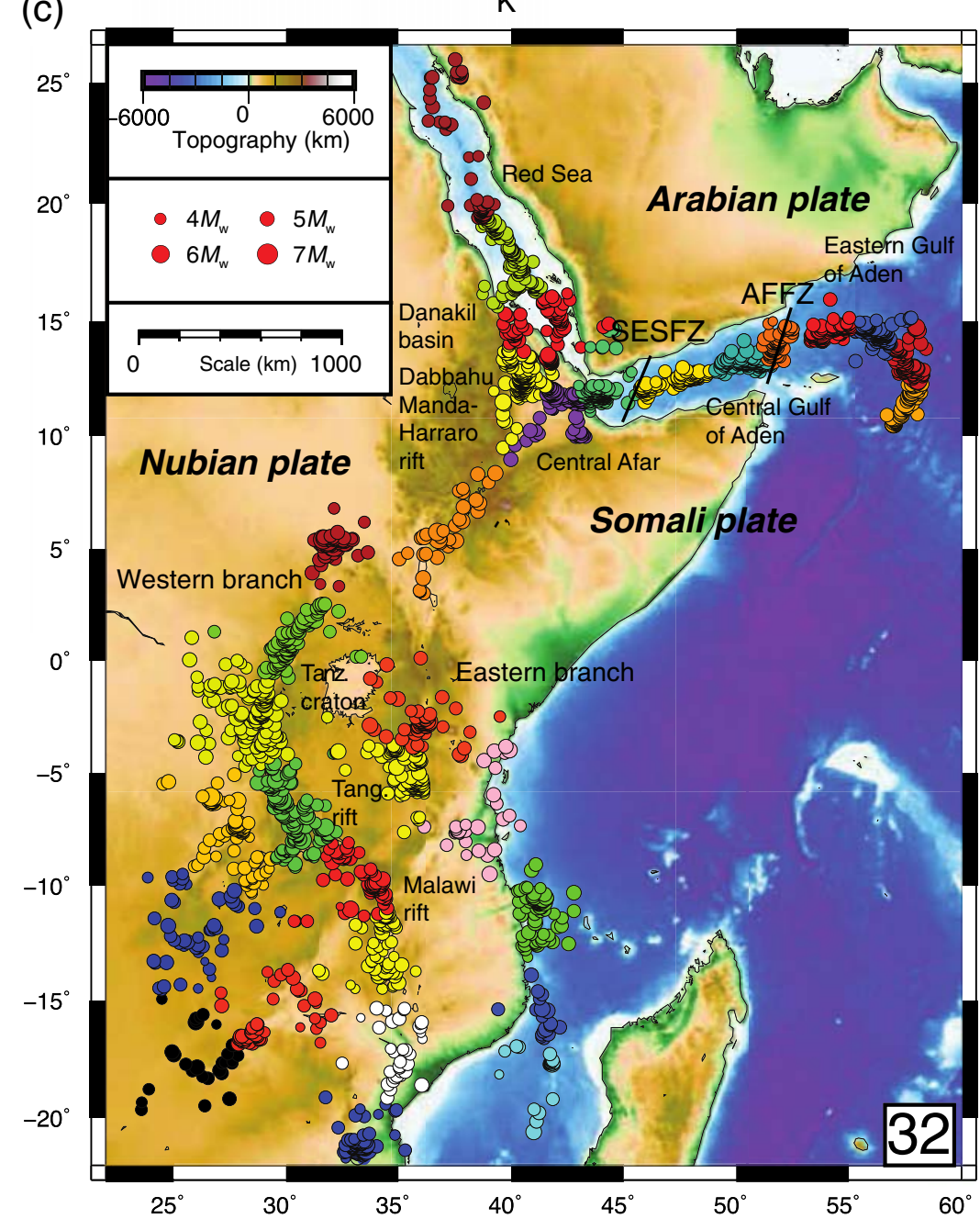

(b)

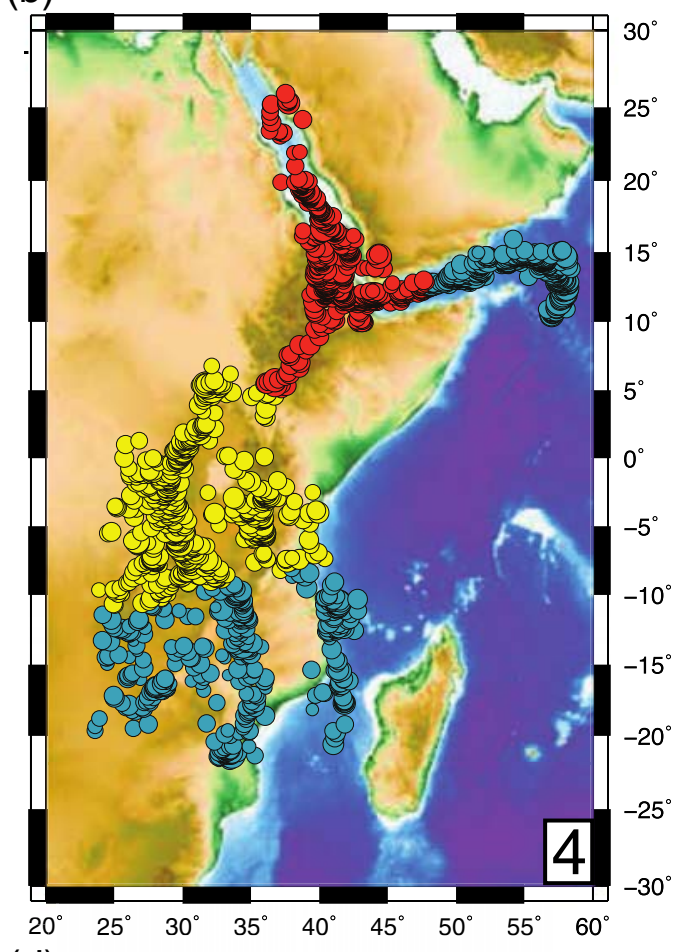

(d)

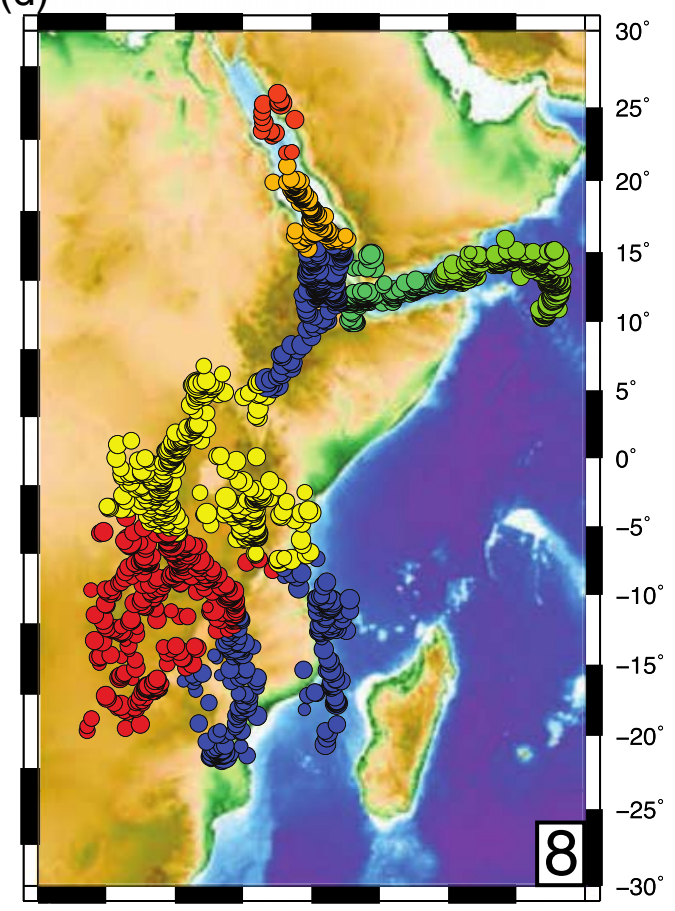

Figure 1. Distribution of National Earthquake Information Center earthquakes during 1973-2013 in Africa and Arabia plotted for the three best-fit $K$-means cluster models. (a) Histogram of Krzanowski and Lai index versus $K$ showing that the 4-, 8-, and 32-cluster models fit best; (b) 4; (c) 8; and (d) 32 clusters. Earthquakes are scaled to magnitude and shaded according to which cluster they are in. The clusters correlate well to morphological basins along the East African rift (EAR). Tang. rift, Tanganyika rift; Tanz. craton, Tanzanian craton; SESFZ, Socotra Hadbeen fracture zone; AFFZ, Alula-Fartak fracture zone. The color version of this figure is available only in the electronic edition.

belts around the deeply rooted Tanzanian craton, causing the rift to bifurcate into two branches (Chorowicz, 2005).

The rift systems show large variations, particularly in the degree of border faulting and axial magma intrusion involved in extension (e.g., Déprez et al., 2014). South of the Main Ethiopian rift (MER) and Kenya rift forming the northern sector of the eastern branch, the majority of the extension occurs on $\sim 60-120$-km-long border fault systems that range from a 
single fault on the rift valley sides to a $<50$-km-wide swath of faulting (e.g., Ebinger et al., 2013). Colinear border faults commonly interact to produce discrete basins that are up to $\sim 200-400 \mathrm{~km}$ in length (Chorowicz, 2005). In contrast, in the MER, Afar, Red Sea, and Gulf of Aden, most of the extension is localized to $\sim 60-100-\mathrm{km}$-long, $<30$-km-wide axial volcanic systems on the floor of the basins where dike intrusion contributes to extension (Wright et al., 2006; Nobile et al., 2012; Barnie et al., 2016). For the Red Sea and Gulf of Aden, the proportion of magma intrusion in extension is thought to increase with proximity to Afar (Bellahsen et al., 2013).

Seismic activity shows variable spatial distribution, depth, and magnitude along the rift. The amount of earthquake activity is the highest in Afar, the Red Sea, and Gulf of Aden primarily due to the faster rate of extension compared to the EAR (Fig. 1d). Along the EAR, the amount of earthquake activity is variable and primarily correlates negatively with the degree of magmatism (Ebinger et al., 2013; Déprez et al., 2014). For example, the magma-rich Ethiopian and Kenya rifts have lower amounts of seismicity than the magma-poor Tanganyika rift in the western branch (Ebinger et al., 2013). The maximum depth and the maximum magnitude of earthquakes increase southward (Craig et al., 2011), a characteristic controlled by the southward increase in lithospheric thickness and strength (Pérez-Gussinyé et al., 2009; Craig et al., 2011) and overall southward decrease in geothermal gradient and decrease in magmatic and volcanic activity (Craig et al., 2011). In this article, we use the $K$-means technique to compute spatial clustering of earthquakes in the EAR, Red Sea, and Gulf of Aden. Once clusters are defined spatially, we compute seismic moment release through time within each cluster, from which we compute maximum credible earthquake (Mcred) and likely the longest time intervals between major releases of seismic energy (Mtime). We use the acronym Mcred to abbreviate the phrase maximum credible earthquake, akin to maximum possible earthquake usage (e.g., Zöller et al., 2013). We then use the quantitative analysis to investigate how along-rift variations in magmatism influence the proportion of extension accommodated by earthquakes.

\section{Data and Methods}

The data are from the National Earthquake Information Center (NEIC) catalog, cover the area of $20^{\circ}-60^{\circ} \mathrm{E}$ and $25^{\circ} \mathrm{S}-30^{\circ} \mathrm{N}$, and are limited to a focal depth of less than $50 \mathrm{~km}$. The final catalog contains 3293 earthquakes within the period January 1973-April 2013 for events greater than $M_{\mathrm{w}} 3.0$, and this seismicity is illustrated in Figure 1. The data were homogenized to the moment magnitude $\left(M_{\mathrm{w}}\right)$ scale using equations

$$
\begin{array}{ll}
M_{\mathrm{w}}=0.67 M_{\mathrm{s}}+2.07 & 3 \leq M_{\mathrm{s}} \leq 6.1 \\
M_{\mathrm{w}}=0.99 M_{\mathrm{s}}+0.08 & 6.2 \leq M_{\mathrm{s}} \leq 8.2 \\
M_{\mathrm{w}}=0.85 M_{\mathrm{b}}+1.03 &
\end{array}
$$

(Scordilis, 2006). The $K$-means data-partitioning method of Hartigan (1975) has made it possible to partition such a regional seismicity into clusters of earthquakes and even into seismic zones (e.g., Greece; Weatherill and Burton, 2009). Indeed, it is possible to partition the seismicity on a long and specific fault into clusters of seismicity that are comparable to the geometry of a geological segmentation. This has been done for the 1800-km-long Sumatran fault (Burton and Hall, 2014) where the partitioned seismicity along the fault (or earthquake clusters), hence fault segments, complements the geological segmentation of Sieh and Natawidjaja (2000). Additionally, in regions where deformation occurs on more distributed fault networks, such as the Aegean, rather than on a single fault strand, the method successfully partitions seismicity in line with the structural segmentation (Weatherill and Burton, 2009).

The procedure to partition seismicity into earthquake clusters is described in detail by Weatherill and Burton (2009) and Burton and Hall (2014), but the procedure is as follows. A cluster is envisaged with a centroid and related surrounding earthquakes. The geographical location of trial centroids is chosen randomly using Monte Carlo techniques, and the procedure starts with two cluster centroids $(K=2)$, then 3,4 , and so on until a reasonable limit has been passed (herein, we investigate the cluster range $K=2-50$ ). For each family of clusters (for $K=2,3,4,5, \ldots$ ), the positions of the centroids are adjusted to minimize the total within-cluster sum of squares (TWCSS)

$$
\operatorname{TWCSS}=\sum_{i=1}^{N} \sum_{k=1}^{K} I\left(x_{i} \in C_{k}\right)\left\|x_{i}-m_{k}\right\|^{2},
$$

in which $N$ is the total number of earthquake locations, $K$ is the cluster number, $x_{i}$ is the location of earthquake $i, m_{k}$ is the mean position of cluster $C_{k}$, and $I(x)$ is 1 if statement $X$ is true, otherwise it is 0 . We conduct 100 trials at each $K .100$ times $K$ centroids are randomly seeded into the data and the algorithm run; the one producing the lowest TWCSS provides the optimum arrangement of centroids at that specific $K$ for that run. Once a set of $K$ models has been derived, the analysis uses the KL index of Krzanowski and Lai (1988) to discern which, if any, of the sets of centroids and cluster partitions fit the whole seismicity better than others. The KL index uses a function of the variance of each cluster model to compare successive differences between the incrementing $K$; that is, the KL value for cluster model $\mathrm{K}$ compares a function of the variance in models $K-1, K$, and $K+1$ to produce the KL index for model $K$. If the data were homogeneous, with no optimum cluster model, then the trend in the successive differences of the variances would follow a steady exponential decay trend. If the data are heterogeneous, that is to say have an optimum cluster model amongst the investigated $K=2-50$ models, the optimum manifests as a strong inflection point in the curve. This inflection point indicates the optimum number of clusters for the data in 
the $K=2-50$ range. Often more than one inflection point will be present in the investigated range of $K$.

We then repeat the above process 1000 times. Meaning that we have 1000 sets of KL values for the cluster models. We calculate the mean KL value for each of the cluster models computed. Cluster models that fit the data well would have achieved a high KL index more often in the 1000 repeats compared to models that do not. To identify a value of $K$ that warrants inspection, we focus on any $K$ that is more than 3 standard deviations away from the mean KL value achieved across all cluster models. We use the same implementation and identification techniques as Burton and Hall (2014) to identify optimum $K$ but increase the amount of repetitions the algorithm goes through from 100 to 1000 , given the larger dataset in this study.

Once a cluster model has been achieved, it is possible to calculate energy or magnitude hazard characteristics of the seismicity within the individual earthquake clusters. Each earthquake cluster is finite in space. Existence of an upper bound to the earthquake magnitude that can be generated by a finite volume of strain energy storage is physically inescapable (Burton and Makropoulos, 1985), as pointed out earlier by Esteva (1976). The mean rate of seismic energy release over time is finite (Knopoff and Kagan, 1978), and Makropoulos and Burton (1983) went on to demonstrate theoretically the existence of an upper bound to seismic energy release (and hence to earthquake magnitude) to maintain that constancy and further developed this concept in a straightforward graphical representation to model and subsequently estimate characteristics of finite zones of seismicity. Makropoulos and Burton (1983) demonstrated that cumulative seismic energy release in a region can thus be used to estimate the Mcred that the region can support after a waiting time (Mtime), or reoccurrence time, assuming that no other significant earthquakes occur during the Mtime years. This model has been applied to several regions, most recently to Bulgaria (Bayliss and Burton, 2013a,b) and also to Turkey (Burton et al., 1984), as well as the Circum-Pacific (Makropoulos and Burton, 1983). Examples of the model for the African-Arabian rift are illustrated in Figure 2. We take each individual cluster as a region in which to calculate the Mcred and waiting time characteristics, and use the equations put forward by Hanks and Kanamori (1979) to relate the seismic moment of an event $M_{0}$ to its moment magnitude $M_{\mathrm{w}}$ :

$$
M_{\mathrm{w}}=2 / 3 \log _{10}\left(M_{0}\right)-10.7 \text {. }
$$

Each graph of seismic moment release against time produces a staircase of the history of energy release in a cluster region (solid staircase line of the specific examples in Fig. 2). The top of the staircase estimates the total energy release in a region during the observation period, and the gradient from origin to this staircase top estimates average annual energy release (Fig. 2). Averages in a physical process tend to be stable, which is why they are used to describe and help define a process. The longer the period of observation, in this case the historical earthquake catalog, then the average annual coseismic energy release is better determined. We have $40 \mathrm{yrs}$ of data, and these estimates are the best available now, although they should inevitably improve in the long term. This average annual coseismic energy release is thus taken to be stationary, and the estimate based on the entire catalog length is the best estimate of this average, rather than an annual recalculation from time origin to each annual step of the staircase in Figure 2. Upper and lower solid lines in Figure 2 are parallel to the annual average coseismic energy release calculated from the available catalog duration; that is, they have the same gradient (annual average coseismic energy release), given that the process is stationary in time (the upper and lower lines envelope all excursions from the mean line).

These cumulative seismic moment release histories are used to estimate the Mcred energy release as the vertical step in energy between upper and lower bounds to the cumulative seismic energy release history in a cluster. Our $M_{\mathrm{w}}$ to $M_{0}$ equation achieves the conversion from maximum credible seismic moment release in an earthquake to the equivalent Mcred magnitude. The model adjusts seismicity identified by the historical earthquake record. The size of historical earthquakes are usually rendered onto a magnitude scale, even if observations were originally macroseismic, and the uncertainty in magnitude is typically about $\sim 0.5$ magnitude units. The more widely observed and better-determined larger earthquakes are accompanied by this typical uncertainty. This $\sim 0.5$ magnitude uncertainty exists in the placing of the upper and lower bounds, which are pinned by the outer excursions in the staircase, usually caused by the larger earthquakes, and accompanies estimates of Mcred. The waiting time to store such a maximum of energy (Mtime) is estimated by the horizontal time interval between upper and lower bounds enveloping the process, thereby making the assumption that no other earthquakes occur to interrupt the storage of this energy.

\section{$K$-Means Cluster Model}

Our cluster analysis finds three most probable models, in which the seismicity is organized into 4,8 , and 32 clusters (Fig. 1a). These models correlate with major structural provinces in the rift system. For the 4-cluster model, the northern cluster includes the predominantly magma-rich rifts of the MER, Afar, the Red Sea, and the western Gulf of Aden (Fig. 1b). The eastern cluster is the more magma-poor eastern Gulf of Aden. To the south, our model defines a discrete cluster in which the EAR bifurcates into the western and eastern branch around the Tanzanian craton. The 8-cluster model defines four clusters in the MER, Red Sea, and western Gulf of Aden, with the EAR divided into a further three clusters (Fig. 1c). However, the 32-cluster model is our preferred model and organizes the seismicity into clusters that are $\sim 100-400 \mathrm{~km}$ in length (Fig. 1d). The boundaries between clusters in the 32-cluster model are preserved in the 8-cluster and 4-cluster models, and the cluster boundaries in the 

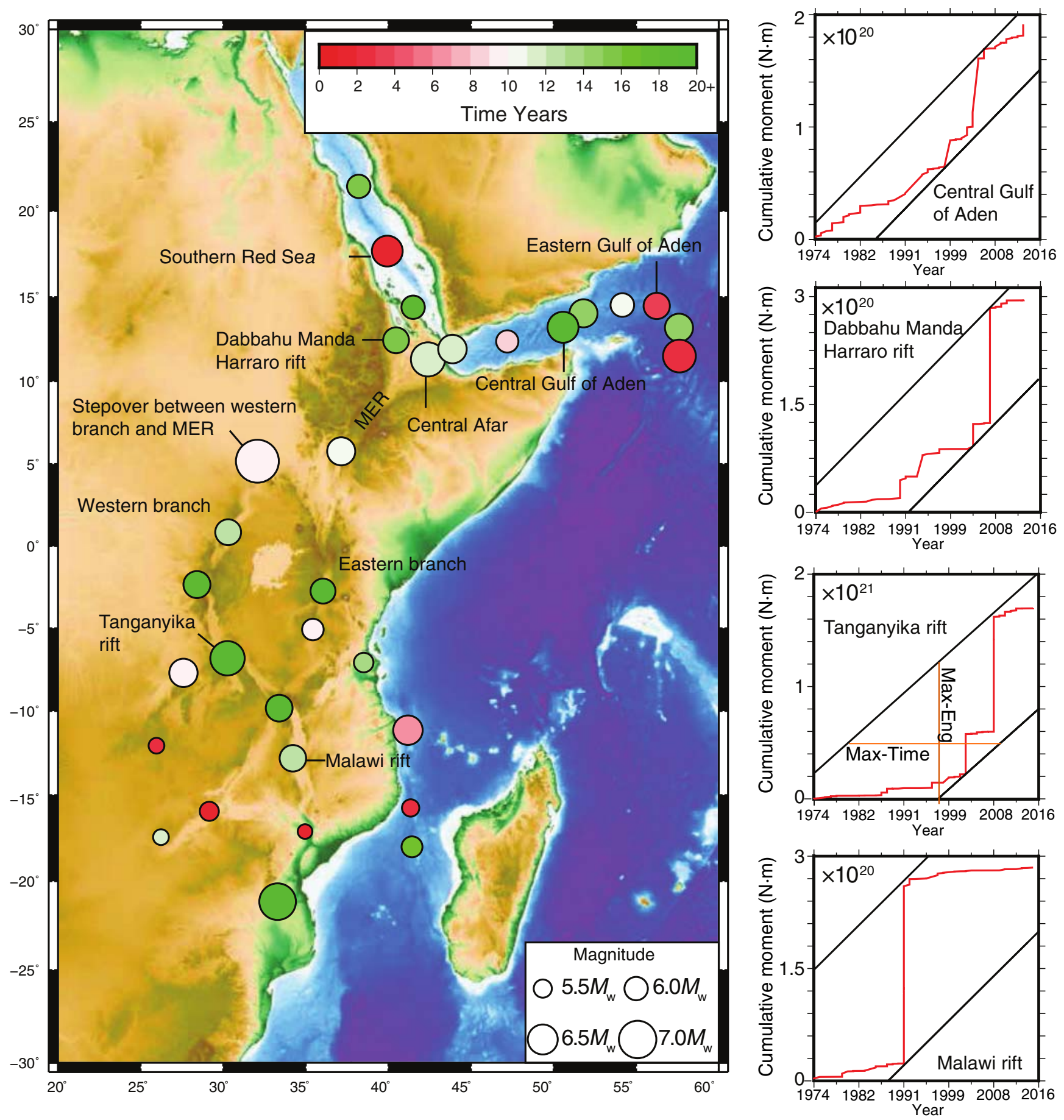

Figure 2. (Left panel) Plot showing Mcred and Mtime for each cluster plotted at the center of the cluster. The results are from the 32 cluster model. Dots are scaled according to Mcred and shaded according to Mtime. (Right panel) Examples of the release of seismic moment release through time in four clusters. Each graph also displays the envelope used to compute Mcred and Mtime. The labels on the Tanganyika rift-energy-release profile show the max-energy and max-time between events. The color version of this figure is available only in the electronic edition.

8-cluster model are preserved in the 4-cluster model, showing internal consistency between models. The major difference between the models is the length scale of the clusters and scale of the geological controls on the segmentation. For example, the 4-cluster model defines clusters of $1500 \mathrm{~km}$ length scale, with cluster boundaries in the EAR near the northern and southern margins of the strong Tanzanian craton around which the rift bifurcates. In the 32-cluster model, boundaries between the clusters are mostly characterized by distinct changes in strike in the long axis of the earthquake clusters, and/or by seismic gaps and lateral steps in earthquake distribution. 
Most clusters in the central and southern portions of the EAR are more than 200-km long and correlate with discrete border fault-controlled basin systems, such as the Tanganyika and the Malawi rifts (Fig. 1d). In the north, the minimum cluster length is smaller at $\sim 100 \mathrm{~km}$, with discrete clusters correlating well with known volcanic systems, such as the Dabbahu-Manda Harraro rift, the Danakil basin, or the less common intrarift magma-poor fault systems, such as Central Afar (Fig. 1d). Along the oblique mid-ocean ridge of the Gulf of Aden, the clusters correlate with either discrete oceanic spreading segments or with major transform faults, such as the AFFZ (Alula-Fartak fracture zone). The 32cluster model spatially correlates very well with discrete morphological sectors in the Red Sea, Gulf of Aden, and EAR, which confirms that along-rift variations in style, amount, and localization of faulting are important in defining spatial zonation of seismicity. We now use the time history of seismic moment release within each cluster to further characterize the deformation pattern and to quantify Mcred and Mtime in these 32 sectors of the rift (Fig. 2).

The 32 clusters show variable patterns of seismic moment release through time (Fig. 2). Mcred varies between $M_{\mathrm{w}} 5.2$ and 7.4 across the whole dataset. The highest computed Mcred is $M_{\mathrm{w}} 7.4$ for the stepover between the northernmost western branch and the southern MER. Variability in Mcred correlates well with degree of magmatism and volcanism along the rift. For example, the Dabbahu-Manda Harraro volcanic system, and the westernmost Gulf of Aden have Mcred values of $M_{\mathrm{w}} 6.2$ and 6.4 respectively, as opposed to the magma-poor Central Afar and Tanganyika rift which both have Mcred values of $M_{\mathrm{w}} 6.8$ (Fig. 2). Along the Gulf of Aden, the two clusters with the highest Mcred values correspond to major transform faults, whereas clusters on spreading segments have lower Mcred values. In addition to estimating the spatial variation in Mcred, we compute Mtime for each cluster (also Fig. 2). As expected, our results show that sectors of the rift that have not experienced earthquakes very recently, such as segments in the southern Red Sea and eastern Gulf of Aden, are the most likely to rupture next. On land, a notable portion of the rift with high Mcred and low Mtime includes Central Afar and the rift stepover between the western branch and the MER, a sector of the rift that includes the recently completed construction of the Tendaho Dam (Ayele et al., 2016). In contrast, the Tanganyika rift and EAR in Mozambique not only have high Mcred but also relatively high Mtime since these sectors experienced large earthquakes in the last decade (Fig. 2).

To test and illustrate the correlation between high values of Mcred with portions of the rift that mainly deform seismically, we compare estimates of the geodetic to seismic moment rate ratio derived by Déprez et al. (2014) to our Mcred for the EAR (Fig. 3). The moment rate ratio varies from values near 1 in the magma-poor western branch to maximum values of between 40 and 80 in Afar and the MER. The results show a positive correlation between large values of Mcred and regions with low geodetic/seismic moment rate

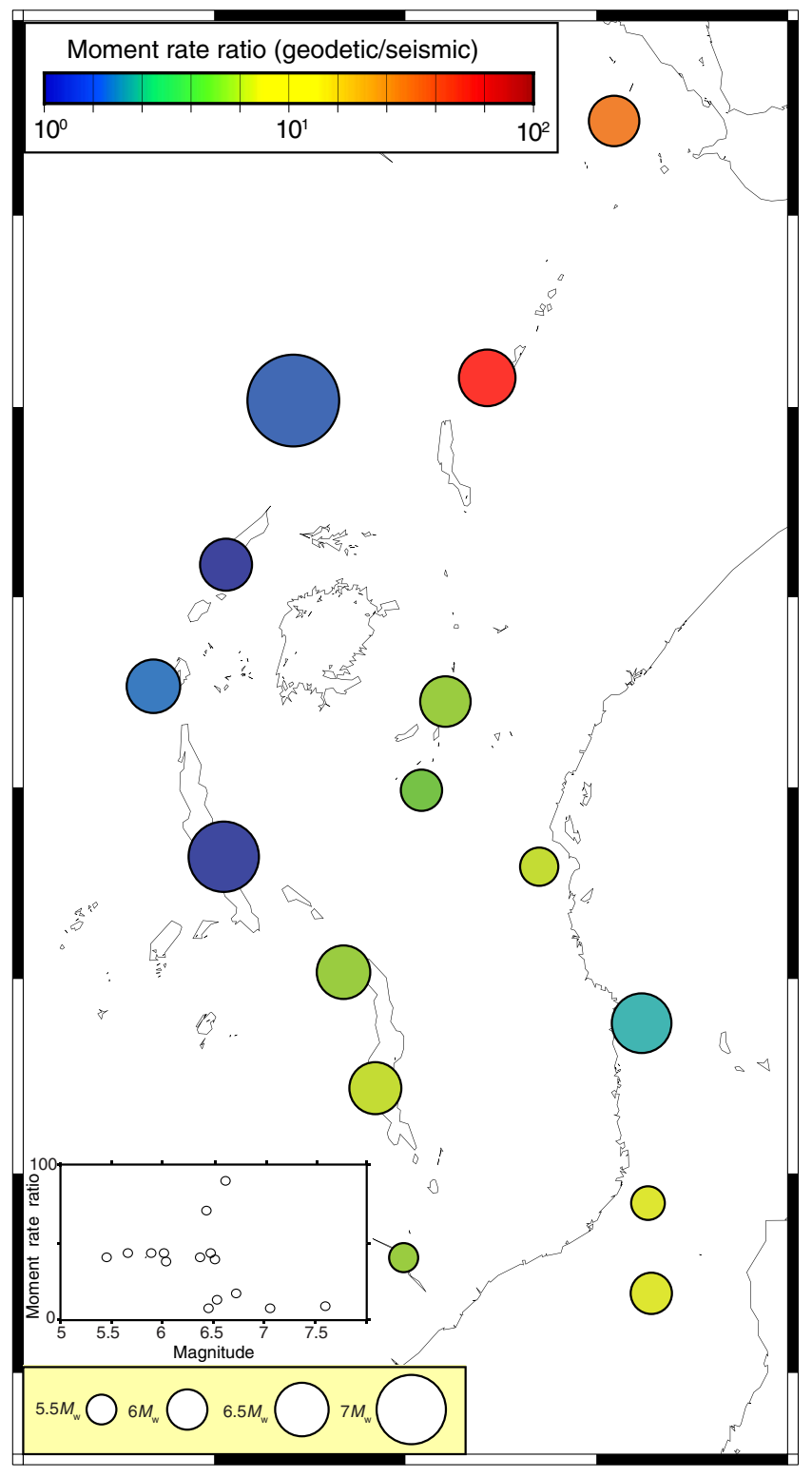

Figure 3. Variation in Mcred and geodetic/seismic moment rate ratio for the EAR. Dots are plotted in the center of each cluster. The moment rate ratio values are from Déprez et al. (2014). The map along with the inset graph shows Mcred plotted against the moment rate ratio and shows a correlation between high Mcred with regions of the rift that deform seismically. The color version of this figure is available only in the electronic edition.

ratio and therefore to regions where the majority of crustal extension occurs by fault slip (Fig. 3). Portions of the rift system where aseismic processes, such as magma intrusion or creep, accommodate significant extension generally are expected to have low-to-moderate values of Mcred. Our cluster maps and computation of Mcred and Mtime provides the first unbiased quantitative framework within which to evaluate structural segmentation of the EAR, as well as the spatially variable earthquake potential along this incipient plate boundary. 


\section{Conclusions}

We conduct $K$-means cluster analysis on seismicity in the African-Arabian rift systems to create the first computationally objective analysis of the pattern of earthquakes in Africa. We use seismic moment to compute spatial variations in maximum credible earthquake and likely time to the next major release of seismic energy. Our cluster analysis finds the three models that are most stable, in which the seismicity is organized into 4,8 , and 32 clusters. These models correlate with major structural provinces in the rift system. Our best-fit model has 32 clusters of $\sim 100-400 \mathrm{~km}$ in length, with cluster size decreasing northward along the rift and cluster boundaries correlating with major structural segmentation of the rift. Boundaries between the clusters are mostly characterized by distinct changes in strike in the long axis of the earthquake clusters and/or by seismic gaps and lateral steps in earthquake distribution. Mcred varies between $M_{\mathrm{w}} 5.2$ and 7.4 across the whole dataset, with the highest values estimated in portions of the rift where the majority of extension is accommodated by seismogenic failure.

\section{Data and Resources}

All data are publically available from the National Earthquake Information Center (NEIC) catalog. The NEIC catalog was last accessed on May 2013.

\section{Acknowledgments}

The authors would like to thank the two anonymous reviewers whose comments helped improve the article. The authors acknowledge that D. K. is supported by Natural Environment Research Council (NERC) Grant NE/L013932/1 and T. R. H. is supported by NERC Grant NE/K500926/ 1. C. W. N. is supported by a VISTA Scholarship in association with the Norwegian Academy of Science and Letters.

\section{References}

Ayele, A., C. J. Ebinger, C. van Alstyne, D. Keir, C. W. Nixon, M. Belachew, and J. O. S. Hammond (2016). Seismicity of the central Afar rift and implications for Tendaho dam hazards, Geol. Soc. Lond. Spec. Publ. 420, 341-354, doi: 10.1144/SP420.9.

Ayele, A., G. Stuart, I. Bastow, and D. Keir (2007). The August 2002 earthquake sequence in north Afar: Insights into the neotectonics of the Danakil microplate, J. Afr. Earth Sci. 48, 70-79, doi: 10.1016/j.jafrearsci.2006.06.011.

Barnie, T. D., D. Keir, I. Hamling, B. Hofmann, M. Belachew, S. Carn, D. Eastwell, J. O. S. Hammond, A. Ayele, C. Oppenheimer, and T. Wright (2016). A multidisciplinary study of the final episode of the Manda Hararo dyke sequence, Ethiopia, and implications for trends in volcanism during the rifting cycle, Geol. Soc. Lond. Spec. Publ. 420, 149163, doi: $10.1144 /$ SP420.6.

Bayliss, T. J., and P. W. Burton (2013a). Seismic hazard across Bulgaria and neighbouring areas: Regional and site-specific maximum credible magnitudes and earthquake perceptibility, Nat. Hazards 68, 271319, doi: 10.1007/s11069-013-0590-5.

Bayliss, T. J., and P. W. Burton (2013b). Erratum to: Seismic hazard across Bulgaria and neighbouring areas: Regional and site-specific maximum credible magnitudes and earthquake perceptibility, Nat. Hazards $\mathbf{6 8}$, 1203-1204, doi: 10.1007/s11069-013-0621-2.
Bellahsen, N., L. Hudson, J. Autin, S. Leroy, and E. d'Acremont (2013). The effect of thermal weakening and buoyancy forces on rift localization: Field evidences from the Gulf of Aden oblique rifting, Tectonophysics 607, 80-97.

Burton, P. W., and T. R. Hall (2014). Segmentation of the Sumatran fault, Geophys. Res. Lett. 41, no. 12, 4149-4158.

Burton, P. W., and K. C. Makropoulos (1985). Seismic risk of circum-Pacific earthquakes. II: Extreme values using Gumbel's third distribution and the relationship with strain energy release, Pure Appl. Geophys. 123, 849-869.

Burton, P. W., R. W. McGonigle, K. C. Makropoulos, and S. B. Ucer (1984). Seismic risk in Turkey, the Aegean, and the eastern Mediterranean: The occurrence of large magnitude earthquakes, Geophys. J. Roy. Astron. Soc. 78, 475-506.

Chorowicz, J. (2005). The East African rift system, J. Afr. Earth Sci. 43, no. $1,379-410$.

Cornell, C. A. (1968). Engineering seismic risk analysis, Bull. Seismol. Soc. Am. 58, 1583-1606.

Craig, T. J., J. A. Jackson, K. Priestley, and D. McKenzie (2011). Earthquake distribution patterns in Africa: Their relationship to variations in lithospheric and geologic structure, and their rheological implications, Geophys. J. Int. 185, 403-434, doi: 10.1111/j.1365-246X.2011.04950.x.

Déprez, A., C. Doubre, F. Masson, and P. Ulrich (2014). Seismic and aseismic deformation along the East African rift system from a reanalysis of the GPS velocity field of Africa, Geophys. J. Int. 193, no. 3, 13531369, doi: $10.1093 /$ gji/ggt085.

Ebinger, C. J., J. van Wijk, and D. Keir (2013). The time scales of continental rifting: Implications for global processes, Geol. Soc. Am. Spec. Pap. 500, 371-396, doi: 10.1130/2013.2500(11).

Esteva, L. (1976). Seismicity, in Seismic Risk and Engineering Decisions, C. Lomnitz and E. Rosenbleuth (Editors), Elsevier Scient. Publ. Comp., Amsterdam, The Netherlands, $425 \mathrm{pp}$.

Goitom, B., M. J. Werner, K. Goda, J.-M. Kendall, J. O. S. Hammond, G. Ogubasghi, C. Oppenheimer, A. Helmstetter, D. Keir, and F. IllsleyKemp (2017). Probabilistic seismic-hazard assessment for Eritrea, Bull. Seismol. Soc. Am. 107, 1478-1494.

Hanks, T. C., and H. Kanamori (1979). A moment magnitude scale, J. Geophys. Res. 84, 2348-2349.

Hartigan, J. A. (1975). Clustering Algorithms, John Wiley \& Sons, Inc., New York, New York.

Jestin, F., P. Huchon, and J.-M. Gaulier (1994). The Somalia plate and the East African rift system: Present-day kinematics, Geophys. J. Int. 116, 637-654, doi: 10.1111/j.1365-246X.1994.tb03286.x.

Knopoff, L., and Y. Kagan (1978). Analysis of the theory of extremes as applied to earthquake problems, J. Geophys. Res. 82, 5647-5675.

Kogan, L., S. Fisseha, R. Bendick, R. Reilinger, S. McClusky, R. King, and T. Solomon (2012). Lithospheric strength and strain localisation in continental extension from observations of the East African rift, $J$. Geophys. Res. 117, no. B3, doi: 10.1029/2011JB008516.

Krzanowski, W. J., and Y. T. Lai (1988). A criterion for determining the number of groups in a data set using sum-of-squares clustering, Biometrics 44, 23-34.

Leroy, S., P. Razin, J. Autin, F. Bache, E. d'Acremont, L. Watremez, J. Robinet, C. Baurion, Y. Denele, N. Bellahsen, et al. (2012). From rifting to oceanic spreading in the Gulf of Aden: A synthesis, Arab. J. Geosci. 5, 859-901, doi: 10.1007/s12517-011-0475-4.

Makropoulos, K. C., and P. W. Burton (1983). Seismic risk of circum-Pacific earthquakes. I: Strain energy release, Pure Appl. Geophys. 121, 247-267.

McClusky, S., R. Reilingerm, G. Ogubazghi, A. Amleson, B. Healab, P. Wernant, J. Sholan, S. Fesseha, L. Asfaw, R. Bendick, et al. (2010). Kinematics of the southern Red Sea-Afar Triple junction and implications for plate dynamics, Geophys. Res. Lett. 37, L05301, doi: 10.1029/2009GL041127.

McKenzie, D. P., D. Davies, and P. Molnar (1970). Plate tectonics of the Red Sea and East Africa, Nature 226, 243-248.

Nobile, A., C. Pagli, D. Keir, T. J. Wright, A. Ayele, J. Ruch, and V. Acocella (2012). Dike-fault interaction during the 2004 Dallol intrusion at the northern edge of the Erta Ale ridge (Afar, Ethiopia), Geophys. Res. Lett. 39, L19305, doi: 10.1029/2012GL053152. 
Papaioannou, C. A., and B. C. Papazachos (2000). Time-independent and time-dependent seismic hazard in Greece based on seismogenic sources, Bull. Seismol. Soc. Am. 90, no. 1, 22-33.

Pérez-Gussinyé, M., M. Metois, M. Fernández, J. Vergés, J. Fullea, and A. R. Lowry (2009). Effective elastic thickness of Africa and its relationship to other proxies for lithospheric structure and surface tectonics, Earth Planet. Sci. Lett. 287, nos. 1/2, 152-167.

Petersen, M. D., S. Harmsen, C. Mueller, K. Haller, J. Dewey, N. Luco, A. Crone, D. Lidke, and K. Rukstales (2007). Documentation for the Southeast Asia Seismic Hazard Maps, USGS, Reston, Virginia, $65 \mathrm{pp}$.

Rehman, K., P. W. Burton, and G. Weatherill (2013). K-means cluster analysis and seismicity partitioning for Pakistan, J. Seismol. 18, no. 3, 401419, doi: 10.1007/s10950-013-9415-y.

Rehman, K., P. W. Burton, and G. A. Weatherill (2017). Application of Gumbel I and Monte Carlo methods to assess seismic hazard in and around Pakistan, J. Seismol. doi: 10.1007/s10950-017-9723-8.

Scordilis, E. M. (2006). Empirical global relations converting $M_{\mathrm{s}}$ and $m_{\mathrm{b}}$ to moment magnitude, J. Seismol. 10, no. 2, 225-236.

Sieh, K., and D. Natawidjaja (2000). Neotectonics of the Sumatran fault, Indonesia, J. Geophys. Res. 105, 28,295-28,326.

Stamps, D. S., G. Iaffaldano, and E. Calais (2015). Role of mantle flow in Nubia-Somalia plate divergence, Geophys. Res. Lett. 42, no. 2, doi: 10.1002/2014GL062515.

Vigny, C., P. Huchon, J.-C. Ruegg, K. Khanbari, and L.-M. Asfaw (2006) Confirmation of Arabia plate slow motion by new GPS data in Yemen, J. Geophys. Res. 111, no. B02402, doi: 10.1029/2004JB003229.

Weatherill, G., and P. W. Burton (2009). Delineation of shallow seismic source zones using $K$-means cluster analysis, with application to the Aegean region, Geophys. J. Int. 176, no. 2, 565-588.

Wright, T. J., C. J. Ebinger, J. Biggs, A. Ayele, G. Yirgu, D. Keir, and A. Stork (2006). Magma-maintained rift segmentation at continental rupture in the 2005 Afar dyking episode, Nature 442, 291-294, doi: 10.1038/nature04978.

Zöller, G., M. Holschneider, and S. Hainzl (2013). The maximum earthquake magnitude in a time horizon: Theory and case studies, Bull. Seismol. Soc. Am. 103, no. 2A, 860-875, doi: 10.1785/0120120013.
Roke Manor Research

Roke Manor

Old Salisbury Lane

Romsey SO51 0ZN, United Kingdom

d.keir@soton.ac.uk

(T.R.H.)

Department of Earth Science

University of Bergen

Allegaten 41

5007 Bergen, Norway

(C.W.N.)

School of Ocean and Earth Science

University of Southampton

European Way

Southampton SO14 3ZH, United Kingdom

(D.K.)

School of Environmental Science

University of East Anglia

Norwich Research Park

Norwich NR4 7TJ, United Kingdom

(P.W.B.)

Institute of Geophysics, Space Science and Astronomy

University of Addis Ababa

King George VI Street

Addis Ababa, Ethiopia

(A.A.)

Manuscript received 9 November 2016; Published Online 9 January 2018 